\title{
Do we need a uniform regulatory system for biobanks across Europe?
}

\author{
Jane Kaye*,1 \\ ${ }^{1}$ Oxford Genetic Knowledge Park, The Ethox Centre, DPHPC, University of Oxford, Headington, Oxford, UK
}

Within Europe, there is currently no uniform regulatory system that applies to human biobanks used for genetic research purposes. This has resulted in considerable variation in the national law that applies to the use of DNA samples, personal information and medical records in the countries across Europe. This could result in a situation where researchers collaborating across Europe may be operating unlawfully if they share research data and samples across borders where different laws are in operation. There are also concerns that the lack of standardised guidelines inhibits cooperation among researchers across Europe but also restricts the sharing of DNA samples and information across national borders, which is problematic for multinational companies and institutions carrying out collaborative research. Ultimately, the lack of a uniform regulatory system may have implications for the viability and long-term competitiveness of collaborative European research. The purpose of this paper is to discuss some of the preliminary issues that would need to be considered before such a regulatory system for biobanks could be developed within Europe.

European Journal of Human Genetics (2006) 14, 245-248. doi:10.1038/sj.ejhg.5201530; published online 23 November 2005

Keywords: biobanks; regulation; Europe; genetic research; law; population genetics

Within Europe, there is currently no uniform regulatory system that applies to human biobanks used for genetic research purposes. This has resulted in considerable variation in the domestic law that applies to the use of DNA samples, personal information and medical records in the countries across Europe. ${ }^{1}$ This means that the secondary research use of biological samples without consent may be allowed in one jurisdiction, such as the UK (Schedule 4, Human Tissue Act 2004), but may be prohibited or restricted to certain types of use in another jurisdiction such as Sweden. This could result in a situation where researchers collaborating across Europe may be operating unlawfully if they share research data and samples across

*Correspondence: Dr Jane Kaye, Oxford Genetic Knowledge Park, The Ethox Centre, DPHPC, University of Oxford, Old Road Campus, Headington, Oxford OX3 7LF, UK.

Tel: + 441865 227074; Fax: + 441865 226938;

E-mail: jane.kaye@ethox.ox.ac.uk

Received 24 February 2005; revised 12 October 2005; accepted 13 October 2005; published online 23 November 2005 borders where different laws are in operation. Scientists have expressed concern that the current regulatory framework for human biobanks within Europe is inadequate. ${ }^{2}$ The main concerns are that the lack of enforceable standards inhibits cooperation among researchers across Europe but also restricts the sharing of DNA samples and information across national borders, which is problematic for multinational companies and institutions carrying out collaborative research. Ultimately, the lack of a uniform regulatory system may have implications for the viability and long-term competitiveness of collaborative European research. If we are serious about developing a regulatory framework for biobanks that facilitates research across Europe and deals with these concerns, the following preliminary issues must be addressed.

\section{What are biobanks?}

One of the major obstacles to developing a uniform system of regulation across Europe is the lack of an agreed 
definition of 'biobank'. It is unclear whether a biobank consists of just DNA samples or whether it includes personal information or data as well. In the literature, there is considerable confusion as to what human biobanks should be called and a number of terms appear, such as 'gene bank', 'genetic biobank', 'knowledge base', 3 'DNA bank', 'genetic database' and 'population genetic database'. With the exception of 'population genetic databases', which is increasingly being used to describe biobanks such as the Icelandic Health Sector Database, which will hold DNA samples and information on most of the people within a defined population or jurisdiction, such as those within a national boundary, and will carry out population genetics, these terms are not based on any agreed definitions or recognised types of biobanks. The reason for this lack of clarity could be due to the fact that we are still in a relatively new field where the distinctions between different types of biobanks are yet to emerge. However, the task of categorising and defining biobanks is not easy. Should we include web-based digital collections such as ENSEMBL, ${ }^{4}$ sample collections made as 'add-ons' for clinical trials or DNA collections established for one-off, specific research projects under the same general heading of biobanks? Should these different kinds of collections be regulated by the same principles or are there fundamental distinctions that require different kinds of regulation?

From 1999 to 2001, the European Commission funded the EUROGENBANK project, which covered six European countries, in order to determine the numbers and types of biobanks that were in existence and what they were used for. The EUROGENBANK study has contacted the managers of biobanks in six countries across Europe and is a first step towards a comprehensive audit. ${ }^{5}$ While this was an excellent project, it did not manage to collect much information on commercially operated biobanks, and only 12 interviews were carried out in the UK, one of the most research active countries within Europe. The project finished in 2001, and in the intervening years, the use of biobanks for research has increased and practice has become more varied, as the use of digital collections has become more important. Further empirical research is required in order to have more up-to-date information on the areas that guidelines or legislation would need to cover.

While it is difficult to discern what kind of biobanks should be covered, it is also difficult to determine how biobanks should be regulated. Before any uniform regulatory system is developed in Europe, there needs to be a careful analysis of current practice regarding biobanks. This would ensure that new legislation had some resonance with current practice and that it did not unnecessarily interfere with the management of existing biobanks. Research is needed to develop a typology of the different types of biobanks that currently exist; the content of the collections; their purposes and uses; the procedures regarding management and access; and how these may vary in the public, not-for-profit and commercial sectors. This could build on the typology that has been developed through the EUROGENBANK project. ${ }^{6}$ Without this comprehensive information, it will not be possible to design and implement a regulatory system that will apply to all types of biobanks, but will also draw on the accumulated wisdom that has developed through practice. Such an analysis may also bring greater conceptual clarity about the differences between biobanks and could result in a reduction in the number of terms that are used to denote biobanks.

\section{What should be covered in regulation?}

It is not sufficient that any new form of regulation should simply enshrine practice, but it also should be based upon a coherent set of principles, to ensure that the law is consistent, effective and relevant for researchers and society. The controversial population biobank proposals, such as the Icelandic Health Sector Database, have led to an extensive international debate over the principles that should be applied to biobanks. This debate has highlighted in particular the need to consider the familial nature of genetic information and the perceived risk to privacy that biobanks may present. The principal issues raised by the debate are: consent, especially for secondary research purposes; ${ }^{7}$ feedback to participants; ${ }^{8}$ benefit sharing; ${ }^{9}$ the public interest; ${ }^{10}$ participation in decision making; ${ }^{11}$ protecting privacy; ${ }^{12}$ access; ${ }^{13}$ ownership; ${ }^{14}$ and intellectual property rights. ${ }^{15,16}$ Sufficient regard must be taken of this literature in order to inform the development of a coherent and principled regulatory structure.

However, it would be wrong to apply all of the principles and procedures recommended for population genetic databases to other kinds of biobanks without carefully considering the implications of doing so. It could be argued that the characteristics of population genetic databases raise specific and unique issues (particularly in relation to privacy), and therefore the principles that have been developed for them do not have relevance for all other types of biobanks. For instance, a blanket requirement that all biobanks should establish their own independent oversight bodies, such as UK Biobank has done, may be unduly burdensome if applied to a collection of several hundred samples, maintained by one research group, for a single research project. It is essential for legislators to be aware of the principles that have developed out of the debate on population genetic databases when developing a uniform regulatory structure for Europe. However, it would be inappropriate to apply these principles to all biobanks without some assessment as to how this might affect current research practice and the management of biobanks that are currently operational across Europe. 


\section{How should biobanks be regulated?}

Currently, within Europe there is no directive or convention that specifically covers the collection, use and storage of DNA samples in biobanks. This raises the issue of whether biobanks should be treated as 'special' and be the subject of separate regulation and governance structures ${ }^{17}$ or whether they should be regulated under a more general legal instrument. The other question that needs to be addressed is what kind of legal instrument should be used, for example, a directive or guidelines, or if less formal regulatory mechanisms such as incentives and sanctions, would be more appropriate.

Despite there being no specific legal instrument within Europe, there is law that impacts on the use of biobanks because it covers the more general areas of personal data, ${ }^{18}$ medical research, ${ }^{19}$ in vitro diagnostic devices, ${ }^{20}$ and clinical trials. ${ }^{21}$ In order to fill this legislative gap, an obvious solution would be to have a directive to cover the use of biological samples, in the hope that this would also cover genetic information. The danger is that the issues that are raised by the nature of genetic information may not be adequately covered by a general legal instrument that covered only biological samples. For instance, if a directive just focused on the biological sample, this would ignore the fact that DNA can be a physical entity but also represented as data at the same time. This would be contrary to clinical practice where no distinction is made between the sample, family histories and the information derived from a sequence. One solution would be to make sure that any new general legislation on biological samples mirrored the legal requirements for the use of identifiable data, but even this may not adequately cover the issues raised by genetic information. For example, any new legal instrument would have to address the familial nature of genetic information, which tests many of the basic tenets of legal doctrine. Current European law focuses predominantly on individual rights, which obscures the fact that genetic information is personal, as well as having implications for the family, the group and the population.

The response to these issues of legislators in Estonia and Iceland has been to develop specialist legislation for population biobanks. While this has served political ends as politicians have been able to be seen to be responding to public concern by instituting systems of oversight and accountability, it has provided solutions to many of the specific issues raised by biobanks. For instance, the Estonian Human Genes Research Act (Inimgeeniuuringute seadus) 2000 makes no distinction between the sample and the personal information of the donor - it all comes under the definition of genetic information. This means that the same consent requirements apply to both the sample and the personal information, as well as for participation in the research project. This suggests that specialist legislation, rather than trying to fit biobanks under existing provisions may be a way forward. However, even if specialist legislation was developed at the European level, it does not mean that this will be implemented uniformly across all member states of the European Union. Recent comparative legal research has shown that there are considerable differences in the laws in different member states of the European Union despite the fact that legislation and regulations often have been based on the same European Directives. ${ }^{22}$ So what other alternatives are there?

The most recent initiative has been by the Council of Europe, which has established a Working Party to draft an Instrument on Research on Stored Human Biological Materials (CDBI-CO-GT2biomat), which may include the consideration of storage of biological materials for research in the future, such as biobanks. ${ }^{23}$ The aim of this protocol is to be far reaching so that biobanks will be considered as a type of biological material. The dilemma is how the issues raised by genetic information will be dealt with under this protocol. One of the limitations of this protocol is that it would only apply to the countries that were signatories to the Convention on Human Rights and Biomedicine. This would mean that countries that had failed to sign the convention, such as the UK, would not be bound by this additional, more specific instrument. This brings into doubt whether this could be considered and will become a European-wide regulatory instrument. At the international level, $\mathrm{HUGO},{ }^{24} \mathrm{WHO}^{25}$ and the $\mathrm{OECD}^{26}$ are developing, or have developed guidelines on biobanks, as have a number of European National Ethics Committees. ${ }^{27}$ However, these are not binding for all European countries, and tend to be statements of principle rather than providing models detailing the standards and procedures as to how data and samples should be stored, protected and used. ${ }^{28}$

This 'hard-law' regulatory approach may not achieve the uniform regulatory framework for biobanks that scientists and researchers seek. An alternative approach has been described by Halliday and Steinberg for the regulation of the nontherapeutic use of human embryonic stem cells in research. ${ }^{29}$ They argue that, instead of relying on regulation at member state level, the European Union could have a significant impact by introducing guidelines for all research funded by the European Commission. There are limitations to this approach when it is applied to biobanks as many are established without European Commission funding. An analysis of the current practice and management of biobanks throughout Europe may provide a basis for determining the best kind of regulatory structure as well as the incentives that could be used to ensure that there was uniform system across Europe.

\section{In conclusion}

There has been an unprecedented increase in the movement of samples and data for use in genetic research across jurisdictional boundaries within Europe and outside of Europe. The current European legal framework does not 
facilitate this activity as there is considerable variation in the law and practice that applies to biobanks in different member states in Europe. Biobanks are currently regulated at a national level through a combination of general laws and oversight bodies, such as research ethics committees, but this is insufficient when samples and data are shared in other countries. One way to safeguard privacy and to protect the interests of participants, while at the same time facilitating collaborative research, is to develop a uniform regulatory structure for biobanks. This would establish common standards, procedures and oversight mechanisms throughout Europe that could be applied to the many types of biobanks that exist. However, the development of a uniform regulatory structure must be based on the following:

- An analysis of current practice to form a basis for the development of models detailing the standards and procedures that need to apply to different biobanks.

- An assessment of the legal and ethical principles appropriate for biobanks.

- An assessment of the different regulatory mechanisms that are currently used in biomedicine within Europe in order to determine how appropriate they are for biobanks.

- A review of current regulatory practice and theory to determine the most appropriate form of regulation for biobanks.

One possible solution maybe the establishment of an independent European body with enforcement powers, or the use of an existing body, to develop models and standards for biobanks that are grounded in an understanding of current practice, based on sound ethical principles and a knowledge of the law. The benefit of such models is that when new biobanks are established, there would not be a need to 're-invent the wheel' - instead there would be an assessment of whether a biobank conformed to a particular model. It would also lead to uniform standards, which would facilitate collaborative, integrated research projects but also protect the interests of research participants. This paper has not provided answers to the dilemma of regulating biobanks, but has simply identified key issues that need to be considered before embarking on such an initiative. Hopefully, this paper will lead to further debate around this issue.

\section{References}

1 Gibbons SMC, Helgason HH, Kaye J et al: Lessons from population genetic databases: a comparison of the law in Estonia, Iceland, Sweden, and the UK. Eur J Health Law 2005; 12: 103-135.

2 Anonymous. Biobanks for Health - Report of a European Union Workshop held in Oslo, Norway, 28-31st January 2003.

3 Claustres $\mathrm{M}$, Horaitus $\mathrm{O}$, Venevski $\mathrm{M}$ et al: Time for a unified system of mutation description and reporting: a review of locusspecific mutation databases. Genome Res 2002; 12: 680-688.

4 http://www.ensembl.org/ (accessed 5th August 2004).

5 Cambon-Thomson A, Hirtzlin I, Preaubert C et al: An empirical survey on biobanking of human genetic material and data in six
European countries; in Knoppers BM (ed):: Populations and Genetics: Legal and Socio-Ethical Perspectives. Leiden/Boston: Martinus Nijhoff Publishers, 2003.

6 Hirtzlin I, Dubreuil C, Praubert N et al: An empirical survey on biobanking of human genetic material and data in six EU countries. Eur J Hum Genet 2003; 11: 475-488.

7 Wright C, Steinberg E, Khoury KK et al: Informed consent for genetic research on stored tissue samples. J Am Med Assoc 1995; 274: 1786-1788.

8 Eriksson S: Should results from genetic research be returned to research subjects and their biological relatives? TRAMES 2004; 8: $46-63$.

9 Wilson S: Population biobanks and social justice: commercial or communitarian models? A comparative analysis of benefit sharing, ownership and access arrangements. TRAMES 2004; 8: $80-90$.

10 Chadwick R, Berg K: Solidarity and equity: new ethical framework for genetic databases. Nat Rev Genet 2001; 2: 318-321.

11 Sharp RR, Foster MW: Involving study populations in the review of genetic research. J Law Med Ethics 2000; 28: 41-51.

12 Laurie G: Genetic Privacy: A Challenge to Medico-Legal Norms. Cambridge: Cambridge University Press, 2002.

13 McEwen JE: DNA data banks; In Rothstein MA (ed): Genetic Secrets: Protecting Privacy and Confidentiality in the Genetic Era. New Haven: Yale University Press, 1997.

14 da Rocha AC: Ethical aspects of human genetic databases: distinctions on the nature, provision, and ownership of genetic information. TRAMES 2004; 8: 34-46.

15 Greely H: Informed consent and other ethical issues in human population genetics. Annu Rev Genet 2001; 35: 785-800.

16 Caulfield T, Upshur REG et al: DNA databanks and consent: a suggested policy option involving an authorization model. BMC Med Ethics 2003; 4: 1-4.

17 Gostin LO, Hodge JG: Genetic privacy and the law: an end to genetics exceptionalism. Jurimetrics 1999; 40: 21-58.

18 Directive 95/46/EC on the protection of individuals with regard to the processing of personal data and on the free movement of such data. Official Journal L 281, 23/11/1995, pp 0031-0050.

19 Convention for the Protection of Human Rights and Dignity of the Human Being with Regard to the Application of Biology and Medicine of 4th April 1997, ETS No. 164.

20 Directive 98/79/EC of the European Parliament and of the Council of 27 October 1998 on in vitro diagnostic medical devices. Official Journal L 331, 7/12/1998, pp 001-0027.

21 Directive 2001/20/EC on the approximation of the laws, regulations and administrative provisions of the Member States relating to the implementation of Good Clinical Practice in the conduct of clinical trials on medicinal products for human use. Official Journal L 121, 1/5/2001, pp 0034-0044.

22 Kaye J, Helgason $\mathrm{HH}$, Nõmper A et al: Population genetic databases: a comparative analysis of the law in Iceland, Sweden, Estonia and the UK. TRAMES 2004; 8: 15-34.

23 Abstract of the 26th meeting of the CDBI, Strasbourg, 16th-19th March 2004. Available at http://www.coe.int/T/E/Legal_Affairs/ Legal_co-operation/Bioethics/CDBI/08abstract_mtg26.asp (accessed 22nd February 2005).

24 HUGO Ethics Committee. 2002. Statement on Human Genomic Databases.

25 World Health Organization. 2003, Genetic databases. Assessing the benefits and the impact on human patient rights.

26 Callan B, Gillespie I: Biobanks from health protection to data protection. Observer OECD, February 2004.

27 Nationaler Ethikrat 2004 'Biobanks for Research - Opinion' and the French Comité Consultatif National d'Ethique 2003, Opinion No. 77.

28 An example is the Italian Society of Human Genetics 2004 Guidelines for Genetic Biobanks http://www.gaslini.org/DPPM/ BIOBANK_GUIDELINES.pdf (accessed 6th July 2005).

29 Halliday S, Steinberg DL: The regulated gene: new legal dilemmas. Med Law Rev 2004; 12: 2-13. 